\title{
The cloud classroom of the skeletal system
}

Deng-Yang Huang ${ }^{a^{*}}$

Chi-Chen Feng ${ }^{b}$

Chih-Kai Peng ${ }^{c}$

Ya-Hsin Chan ${ }^{d}$

Chih-Chieh Hu

Suggested Citation:

New Trends and Issues Proceedings on Humanities and Social Sciences.

Abstract 
Issues Proceedings on Humanities and Social Sciences.

1. Introduction

2. Related Work

2.1. The influence of e-learning on teaching

2.2. The current status of e-learning applications 
Issues Proceedings on Humanities and Social Sciences.

\subsection{The Benefits the ARCS Model brings to Teaching}

2.4. The integration of clouds, social groups, and games

3. System Architecture 


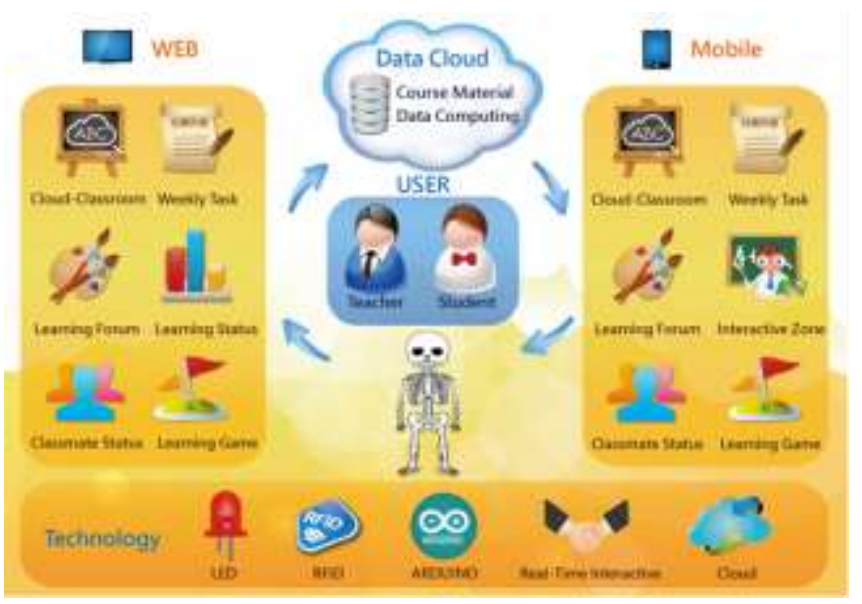

\section{Implementation}

Figure 1. The cloud classroom of the skeletal system system architecture

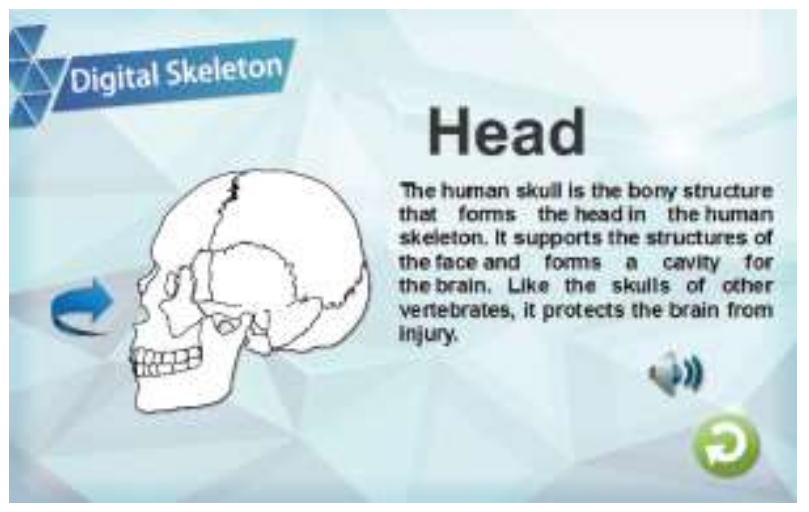

Figure 2. The mobile device platform 
Issues Proceedings on Humanities and Social Sciences.

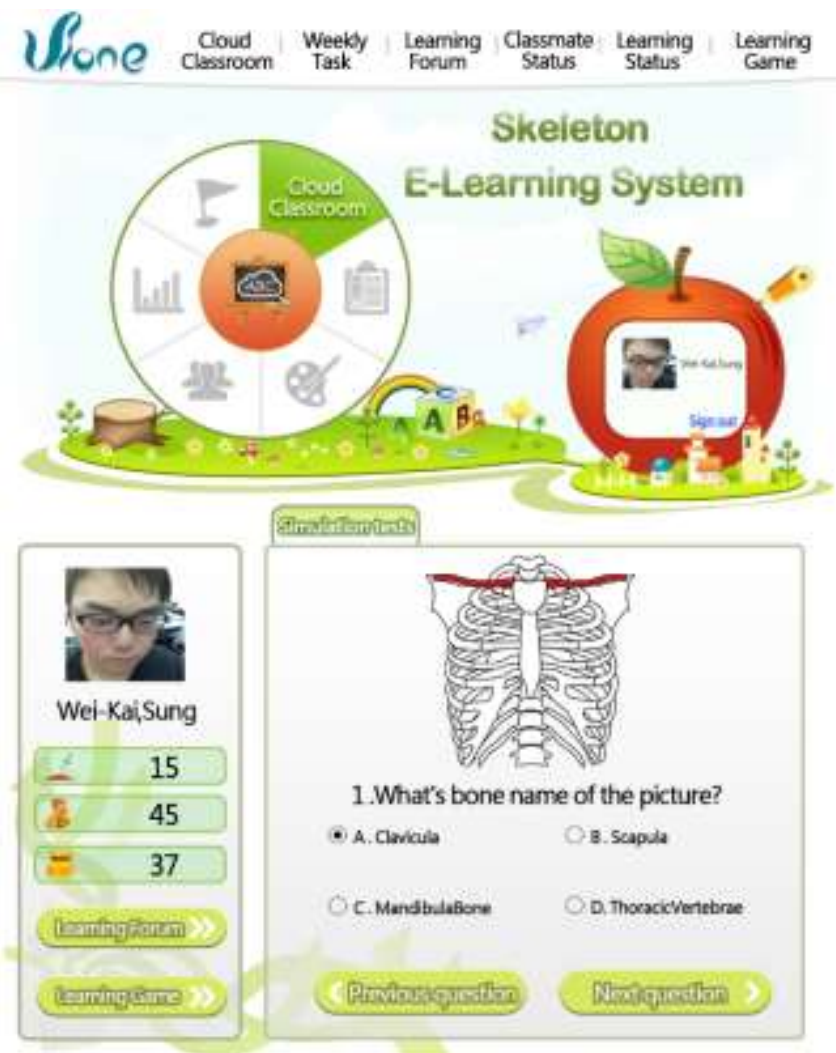

Figure 3. The Exams of Skeleton System

\section{Conclusion}




\section{Medical Education, 34}

Journal of Instructional

Development, 10

Academic

Medicine, 84 